\title{
Effect of lysolecithin on gastric mucosal structure and potential difference
}

\author{
R. ORCHARD, K. REYNOLDS, B. FOX, R. ANDREWS, R. A. PARKINS, AND \\ A. G. JOHNSON 1
}

From the Departments of Surgery, Ilistopathology, and Gastroenterology, Charing Cross Hospital, London

SUMMARY The effect of lysolecithin $(100 \mathrm{mg} \%$ ) on the guinea-pig gastric mucosa was studied by instilling a solution for 30 minutes, preceded and followed by $100 \mathrm{MN} \mathrm{HCl}$ into 10 total gastric pouches. Ten control animals had $\mathrm{HCl}$ throughout. Lysolecithin produced a significant change in transmucosal potential difference, macroscopic erosions, and mucosal damage on histology and electron scanning microscopy. None of these changes was seen in the control animals. This is further evidence that the reflux of lysolecithin from the duodenum is an important factor in causing active gastritis and gastric erosions.

A number of substances including bile salts, aspirin, and lysolecithin have been found to break the gastric mucosal barrier and produce sodium and hydrogen ion flux across the mucus membrane. When Davenport (1970) first performed these studies he did not correlate the chemical changes with structural damage to the gastric mucosa. The purpose of the present investigation was to measure changes in the transmucosal potential difference (TMPD) at the same time as studying changes shown by light microscopy and scanning electron microscopy (SEM). Lysolecithin, a phospholipid produced by the action of the phospholipase in pancreatic juice on the lecithin in bile, is well known to damage cell membranes. We have found this substance in high concentrations in the night gastric juice of patients with gastric ulcer but not in normal subjects (Johnson and McDermott, 1974). These concentrations were similar to those that Davenport had found to break the gastric mucosal barrier, and we therefore thought it important to see whether lysolecithin also produced structural damage of the mucosa.

\section{Methods}

A guinea-pig total gastric pouch preparation was designed to measure transmucosal potential and assess morphological change after instillation of lysolecithin. The basic requirements the preparation fulfilled were: (1) adequate unhandled and un-

${ }^{1}$ Requests for reprints to A. G. J.

Received for publication 26 November 1976 traumatised material suitable for scanning electron microscopy and light microscopy; (2) instillation and complete recovery of test solutions; (3) a stable and reproducible method of measuring TMPD.

Twenty such pouches were constructed. Before surgery all animals were starved for 48 hours to ensure there were no food residues in the stomach. Under halothane and oxygen anaesthesia the intraabdominal portion of the oesophagus was ligated. Through a duodenostomy in the second part of the duodenum a $2 \%$ Agar $\mathrm{KCl}$ electrolyte bridge attached to a 6 FG cannula was passed carefully into the stomach via the pylorus. The duodenum was ligated to avoid leakage around the tube. The average pouch volume was $30 \mathrm{ml}$. The transmucosal potential difference was measured by using the intragastric electrolyte bridge in combination with a similar subcutaneous electrode. The distal ends of the bridges were placed in beakers of saturated $\mathrm{KCl}$ and the potential difference between them measured via calomel $\frac{1}{2}$ cell electrodes connected to a Radiometer millivolt meter.

The following solutions were instilled into the pouch: (1) $100 \mathrm{MN} \mathrm{HCl}$; (2) lysolecithin $100 \mathrm{mg} \%$ in $20 \mathrm{ml}$ phosphate buffer, $\mathrm{pH} 7 \cdot 4$. Before the start of each experiment the pouch was carefully irrigated to remove resting juice and any food debris.

In 10 experiments $20 \mathrm{ml} 100 \mathrm{MN} \mathrm{HCl}$ was instilled into the pouch and changed at 30-minute intervals, for a period of $1 \frac{1}{2}$ hours. These pouches acted as controls for both morphological damage and measurement of TMPD. In the other 10 experiments, 
after a 30-minute stablisation and control period with $100 \mathrm{MN} \mathrm{HCl}$, the pouch was drained and $20 \mathrm{ml}$ lysolecithin instilled. The pouch was drained after 30 minutes and the solution replaced with $20 \mathrm{ml}$ $100 \mathrm{MN} \mathrm{HCl}$. Throughout the three periods TMPD was measured continuously. At the end of the experiments the $\mathrm{HCl}$ was drained and instant fixation of the gastric mucosa was obtained by instilling glutaraldehyde. The total gastric pouch was removed. Macroscopic lesions were assessed after adequate fixation. Strips of mucosa $0.5 \mathrm{~cm}$ wide extending from fundus to antrum were removed. Alternate strips were sent for scanning electron microscopy and light microscopy. Changes in TMPD were recorded at five-minute intervals and plotted as shown in Fig. 1. The light microscopy was assessed by an experienced histopathologist unaware of whether the sections came from a lysolecithin or control animal.

The strips for scanning electron microscopy were critical point dried, sputter coated with gold and photographed at magnifications between $\times 10$ and $\times 2000$ on a VG Miniscan scanning electron microscope.

\section{Results}

These can be classified under changes in TMPD, macroscopic appearance, light microscopy, and scanning electron microscopy.

TRANSMUCOSAL POTENTIAL DIFFERENCE

Figure 1a shows the results of TMPD in one experiment. The overall changes in TMPD were calculated as the difference between the mean readings in the first and third 30-minute periods-that is, when $\mathrm{HCl}$ was in the pouch in both lysolecithin and control animals. The Table gives the results. Figure $1 \mathrm{~b}$ shows a control study where no lysolecithin was used. The mean change in TMPD for all experiments was $+8.5 \mathrm{mV}(23.3 \%)$ as against 0 for the controls, the mucosal pole being negative in relation to the serosal pole.

Table Changes in TMPD after installation of lysolecithin

\begin{tabular}{lll}
\hline Gastric pouch & Change in $\mathrm{mV}+$ & $\%$ Change \\
\hline A & $6 \cdot 3$ & $21 \cdot 0$ \\
B & $8 \cdot 3$ & $26 \cdot 9$ \\
C & $10 \cdot 2$ & $28 \cdot 6$ \\
D & $3 \cdot 1$ & $9 \cdot 4$ \\
E & Unstable figures & \\
F & $12 \cdot 4$ & $35 \cdot 0$ \\
G & $8 \cdot 6$ & 24.9 \\
H & $7 \cdot 4$ & $16 \cdot 3$ \\
I & $11 \cdot 6$ & $28 \cdot 7$ \\
J & $8 \cdot 2$ & $19 \cdot 1$ \\
\hline
\end{tabular}

\section{MACROSCOPIC CHANGES}

Figure 2 shows the guinea-pig stomach filled with glutaraldehyde at the end of an experiment. There are a number of acute haemorrhagic ulcers. Eight out of 10 stomachs after lysolecithin showed multiple erosions; one of the control animals showed a single very small erosion.

\section{HISTOLOGICAL CHANGES}

There was focal and diffuse desquamation of the superficial mucosa with marked oedema and loss of normal architecture (Fig. 3a) in all of the sections in the lysolecithin animals, except those from animai $D$. In all of the lysolecithin animals there was increase in neutrophils in the blood vessel of the mucosa and serosa and in places perivascular infiltration by



(a)

(b)

Fig. 1 (a) Example of changes in TMPD after lysolecithin.

(b) Example of changes in TMPD in control animal. 


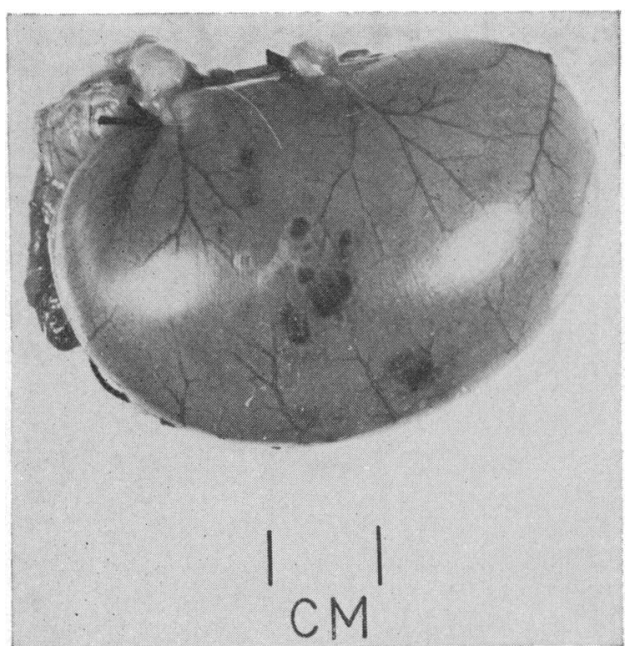

Fig. 2 The intact stomach after lysolecithin showing mucosal erosions.

neutrophils and mononuclear cells. In the animals that had not received lysolecithin the mucosa was normal and there was no infiltration by inflammatory cells (Fig. 3b). We have not attempted to correlate quantitatively, the degree of mucosal damage with the changes in TMPD but it is interesting that pouch $\mathrm{D}$ did show the least disruption of the surface and pouches $\mathrm{C}$ and $\mathrm{F}$ the most severe desquamation and loss of structure.

\section{SCANNING ELECTRON MICROSCOPIC CHANGES}

These changes were easily seen and dramatic. Figure 4a shows mild changes with focal desquamation and Fig. $4 \mathrm{~b}$ moderately severe diffuse desquamation of surface cells. Figure $4 \mathrm{c}$ shows the normal gastric mucosa. All the lysolecithin treated stomachs showed a mild to moderate degree of desquamation except in animal D. The scanning EM changes correlated well with epithelial changes seen on light microscopy, but light microscopy revealed the deep mucosal inflammation not seen on EM.

\section{Discussion}

It is important to distinguish between sodium and hydrogen ion flux and changes in transmucosal potential difference. Although these fluxes as measured by Davenport (1970) indicate damage to the mucosal barrier, they may not be the only factors responsible for the change in TMPD. The term 'back diffusion of hydrogen ions', although popular, may be misleading. This study has shown that when lysolecithin is instilled into a gastric pouch, followed by hydrochloric acid, two things happen: (1) there is a significant change in TMPD



(a) (b)

Fig. 3 (a) Histological changes after lysolecithin. $H$ and $E \times 120$ (original magnification). (b) Absence of histological charges in control. $H$ and $E \times 120$ (original magnification). 
(a)

(b)

Fig. 4 (a) Mild surface changes on SEM after lysolecithin. $\times 500$ (original magnification). (b) Moderately severe surface changes on SEM after lysolecithin $\times 500$ (original magnification).

(c)

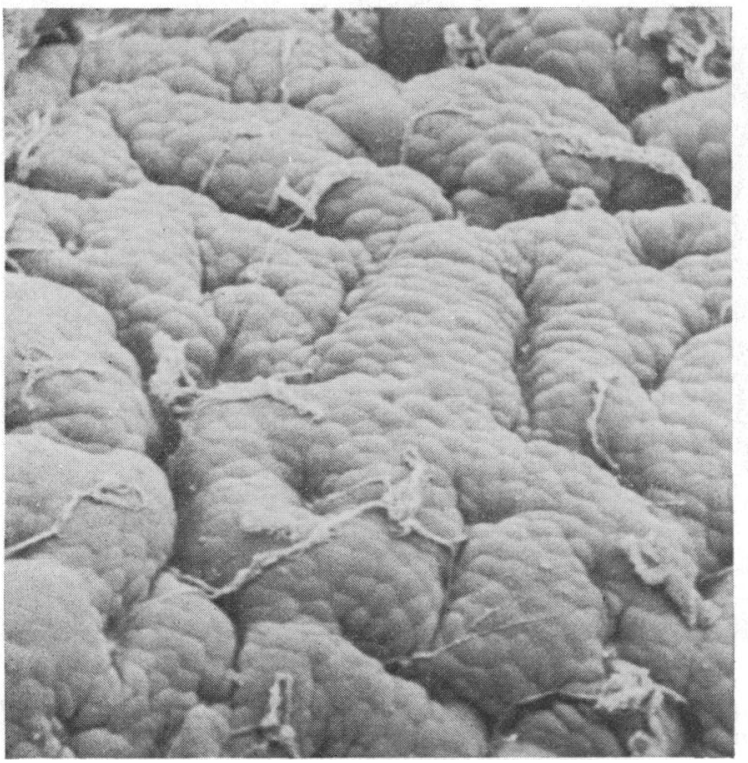

(c) Absence of surface changes in a control stomach $\times 500$ (original magnification).



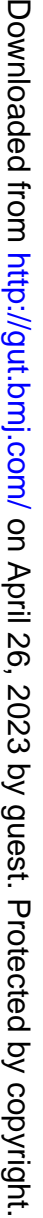


while the lysolecithin is present and after acid has been reintroduced; (2) there is structural damage to the mucosa detected by three different methods. It does not explain whether the hydrogen ions going into the mucosa cause the damage or whether the damage allows the leak of hydrogen ions. Other chemicals such as aspirin and bile salts give similar changes (Orchard, unpublished observations), but Davenport found that bile salts in concentrations found in human stomachs (Rhodes et al., 1969) produced very little change, whereas the lysolecithin concentrations used here were those found in patients. Kivilaakso et al. (1975) studying experimental stress ulcers in the porcine stomach, found that prevention of duodeno-gastric reflux prevented the development of ulcers but instillation of lysolecithin allowed the ulcers to develop. In many patients duodenogastric reflux is an intermittent phenomenon where the stomach is sometimes bathed in duodenal juice and sometimes in acid. Our experimental model mimics well this clinical situation, and the inflammatory changes in the mucosa produced by lysolecithin are similar to those seen in patients with active gastritis.

\section{Conclusion}

Lysolecithin in the guinea-pig stomach produces changes in TMPD associated with definite macroscopic and microscopic lesions on light microscopy and scanning EM. This adds further support to the theory that reflux of duodenal juice, and lysolecithin in particular, is an important factor in causing gastric mucosal damage.

We are grateful to Dr. P. Eaton and the staff of the Animal Unit for their assistance and to Mr. S. Ganley and the Medical Illustration Department for the figures.

\section{References}

Davenport, H. W. (1970). Effect of lysolecithin, digitonin and phospholipase A upon the dog's gastric mucosal barrier. Gastroenterology, 59, 505-509.

Johnson, A. G., and McDermott, Susan J. (1974). Lysolecithin: a factor in the pathogenesis of gastric ulceration? Gut, 15, 710-713.

Kivilaakso, E., Ehnholm, C., Kalima, T., and Lempinen, M. (1976). Duodenogastric reflux of lysolecithin in the pathogenesis of experimental porcine stress ulcer. (Abstracts of the 10th Congress of the European Society for Experimental Surgery, Paris, 1975.) European Surgical Research, 8, suppl. 2, 55-56.

Orchard, R. (1976). Unpublished observations.

Rhodes, J., Barnardo, D. E., Phillips, S. F., Rovelstad, R. A., and Hofmann, A. F. (1969). Increased reflux of bile into the stomach in patients with gastric ulcer. Gastroenterology, 57, 241-252. 